\title{
Reanalysis of the Benešov bolide and recovery of polymict breccia meteorites - old mystery solved after 20 years
}

\author{
Pavel Spurný ${ }^{1}$, Jakub Haloda ${ }^{2,3}$, Jiří Borovička ${ }^{1}$, Lukáš Shrbený ${ }^{1}$, and Patricie Halodová \\ 1 Astronomical Institute, Academy of Sciences, 25165 Ondřejov, Czech Republic \\ e-mail: pavel.spurny@asu.cas.cz \\ 2 Czech Geological Survey, Geologická 6, 15200 Praha 5, Czech Republic \\ 3 Oxford Instruments NanoAnalysis, Halifax Road, High Wycombe, HP12 3SE, UK
}

Received 30 May 2014 / Accepted 5 September 2014

\begin{abstract}
The main motivation for this work was to explain and solve the old mystery connected with the detailed instrumental observation of the Benešov superbolide on 7 May 1991 over the central part of the Czech Republic. Detailed analyses of this undoubted meteorite fall were published in several papers, and this is one of the best documented bolides (at least of the superbolide category) ever observed. However, despite high-quality data, favorable trajectory, relatively large terminal mass, and especially great efforts and many attempts, no meteorite was found in the weeks and years after the fall. Here we solve and explain this old mystery. In spring 2011, just before the twentieth anniversary of this extraordinary case, we remeasured all available all-sky records and reanalyzed the data. We used slightly different methods and new approaches, which we gradually developed to analyze several recent instrumentally observed meteorite falls (Morávka, Neuschwanstein, Jesenice, Bunburra Rockhole, Mason Gully, and Košice). We assembled a new consistent picture of the Benešov event, which resulted in a slightly revised impact location and suggested a new strategy that might lead to a recovery of Benešov meteorites after 20 years. The reality completely confirmed all our assumptions and surpassed our expectations. We found

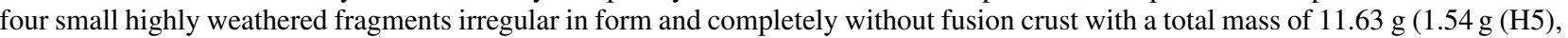
$7.72 \mathrm{~g}$ (with achondritic clast), $1.99 \mathrm{~g}, 0.38 \mathrm{~g}$ (all LL3.5)). They were recovered exactly in the predicted impact area for corresponding masses, namely within $40 \mathrm{~m}$ from the highest probability line. Although all fragments are very small and their weathering grade is high (W3 for all pieces), their interior was preserved enough for reliable analysis (except for the smallest one). The meteorite is classified as a polymict breccia containing three recognized lithologies with different texture, chemical, and mineralogical composition. This result is pioneering in many aspects. We proved that in some special cases it is still possible to predict and find meteorites a long time after the fall. The most important result, however, is the heterogeneity of the recovered meteorites. This case clearly shows that larger meteoroids can be compositionally very complicated bodies. We discovered that the Benešov meteoroid consisted of at least three different types of material - LL3.5, H5, and primitive achondrite. This case also implies that it is very useful to study as many fragments as possible from one fall because there can be significant differences among them.
\end{abstract}

Key words. meteorites, meteors, meteoroids

\section{Introduction}

Collisions of large meter-sized meteoroids with the Earth's atmosphere are relatively rare events. According to Brown et al. (2002, 2013), there are on average 40 such interplanetary bodies colliding with Earth per year. These collisions cause very spectacular so-called superbolide events, which when they occur over ground, usually attract significant attention among local people across a large area of several tens of thousand square kilometers. However, only very few of these events are so well documented that a detailed study of their atmospheric flights and a reliable determination of their atmospheric trajectories and heliocentric orbits is possible.

One of the best cases of instrumentally documented collisions of meter-sized meteoroids is the superbolide recorded during the systematic photographic observations of fireballs in the Czech part of the European Fireball Network (EN) on 7 May 1991 at $23^{\mathrm{h}} 03^{\mathrm{m}} 44-49^{\mathrm{s}}$ UT, well known as the Benešov bolide. This extraordinary event was recorded by four all-sky and two spectral cameras at three Czech stations of the EN; it reached maximum absolute brightness of -19.5 mag (Borovička \& Spurný 1996). Data on atmospheric trajectory, heliocentric orbit, fragmentation history, photometry, composition, and possible impact location based on detailed analysis of all these available photographic records were published in several papers, for instance, Spurný (1994), Borovička \& Spurný (1996), Borovička et al. (1998a,b), and Ceplecha \& ReVelle (2005). It makes this event one of the best described and comprehensively studied bolide in history. Moreover, this meteoroid penetrated very deep into the atmosphere (the last photographed point was at a height of only $19 \mathrm{~km}$ ), and already from the initial analysis (Spurný et al. 1991) it was evident that it certainly ended in a multiple meteorite fall. Despite great efforts and many attempts, no meteorite was found in the weeks and years after the fall. At the time of Benešov bolide only three instrumentally observed meteorite falls were known, Příbram (Ceplecha 1961), Lost City (McCrosky et al. 1971), and Innisfree (Halliday et al. 1978), and it was quite a frustrating situation that from such a favorable case we were not able to find any meteorite in the predicted area. From the aspect of probability of a meteorite find, it was certainly the most promising case, at least over central Europe, after the famous Příbram meteorite fall, which was the first photographically documented fall in history (Ceplecha 1961). Although the impact area was not so favorable 
for searching because a significant part was covered by dense vegetation, mostly by forests and bushes, it was suspicious that no meteorite was found.

In the two decades following the Benešov fall, we have improved our reduction procedures and measurement and computation methods (Borovička et al. 1995; Spurný 1997) and analyzed many new fireballs. Thanks to this improved and verified correctness, we were able to successfully predict locations of meteorites for several of these fireballs. This in turn enabled us to describe the main processes that accompany the atmospheric flight of larger meteorites much more precisely, especially flights that terminate in meteorite falls. We gained the experience for our improved predictions from analyzing instrumentally observed meteorite falls at Morávka in the Czech Republic in 2000 (Borovička et al. 2003), Neuschwanstein in Austria/Germany in 2002 (Spurný et al. 2003), Villalbeto de la Peña in Spain in 2004 (Trigo-Rodríguez et al. 2006), Bunburra Rockhole in SW Australia in 2007 (Bland et al. 2009; Spurný et al. 2012), Jesenice in Slovenia in 2009 (Spurný et al. 2011), Košice in Slovakia in 2010 (Borovička et al. 2013a), and Mason Gully again in SW Australia in 2010 (Spurný et al. 2011). These cases differ significantly from each other, because they cover a wide variety of cases with different structural properties, different scenarios of atmospheric flight, and a wide range of initial masses from tens of kilograms to several tons. Our methods were summarily verified in particular by the very precise prediction of the Bunburra Rockhole meteorite fall (Spurný et al. 2012), where all three meteorites were found within $100 \mathrm{~m}$ of the predicted central line and in the predicted mass range, and for which the dark-flight was computed from as high as $30 \mathrm{~km}$ altitude; the flight lasted $6 \mathrm{~min}$ for a $100 \mathrm{~g}$ meteorite.

All these circumstances were the main motivation to return to the Benešov bolide and try to solve its long-lasting mystery because we continued to wonder what was amiss in this particular case. Therefore in spring 2011, just before the twentieth anniversary of this extraordinary event, which was the incentive to revise it, we remeasured all available all-sky records and reanalyzed these data.

Here we describe in detail the method by which we obtained a new consistent picture of the whole event. We derived a slightly revised atmospheric trajectory, impact location, and new scenario of the meteorite fall. It allowed us to use a new strategy that led to the recovery of the Benešov meteorites after 20 years exactly in the newly predicted area. We also discuss the circumstances of the meteorite finds and describe and classify them and their properties.

\section{Instrumental records and summary of the old results}

The Benešov bolide was photographed by three fixed all-sky cameras at three Czech stations: Ondřejov, Telč, and Přimda, and by one guided fish-eye camera at Ondřejov. All these manually operated all-sky cameras were equipped with the very precise Zeiss Distagon fish-eye lens $(f / 3.5, f=30 \mathrm{~mm})$, which provided us with the high-resolution all-sky image of the whole hemisphere with a diameter of $80 \mathrm{~mm}$ (measuring precision was about 5 microns). All fixed cameras had a rotating shutter close to the focal plane that caused 12.5 interruptions per second on the luminous path of a fireball. Photographic plates ORWO NP27 with panchromatic emulsion were used. The simultaneously operated guided camera at Ondřejov with the same lens served to determine the time of the fireball passage. Note

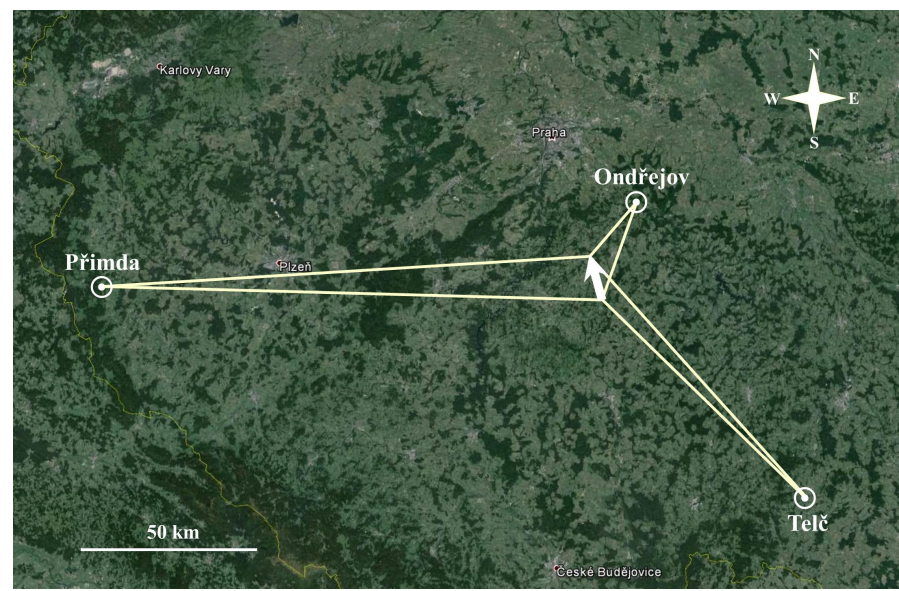

Fig. 1. Distribution of the stations where Benešov bolide was photographed in respect to the projected bolide trajectory (source of maps: Google Earth).

that the fireball was so bright that the two all-sky images from Ondřejov were highly overexposed. They can be used practically only to determine the trajectory position and not to determine the velocity because shutter breaks are not resolved except for short parts near the beginning and end of the trajectory. The fireball was so bright in Ondřejov that it turned deep night into broad daylight (the fireball flew in the moonless night just after the local midnight). The apparent brightness of the brightest flare, which was only $32 \mathrm{~km}$ from the Ondřejov cameras, reached $-21 \mathrm{mag}$. In addition to these direct photographic images, two very detailed spectral records covering the whole luminous trajectory were taken with two long-focus cameras (lens Tessar $f / 4.5, f=360 \mathrm{~mm}$ ) equipped with 400 and 600 groves $/ \mathrm{mm}$ gratings, respectively. Both records covered zero, first, and partly also second order. The spectrum is very rich and contains many atomic lines, molecular bands as well as continuous radiation (in the region of the brightest flare) and still remains after more than 20 years the best spectrum ever obtained for such a big meteoroid of the superbolide category. These spectra were described in Borovička \& Spurný (1996) and Borovička et al. (1998b) and are not discussed further here. A new analysis of the molecular radiation is in preparation (Berezhnoy \& Borovička 2014). However, because these high-resolution images contain the zero order, they were both also used to determine the trajectory, which is one of the main subjects of interest of this paper.

The distribution of the stations with respect to the bolide trajectory is shown in Fig. 1. The basic data of the geographic coordinates, distances to the bolide trajectory, range of recorded heights and lengths of the luminous path for individual cameras are collected in Table 1. The number and quality of all these records and their distribution around the bolide trajectory is very favorable and suitable to very precisely determine all parameters describing atmospheric flight and original orbit in the solar system of this extraordinary event. Moreover, this very favorable geometry is supported by the almost vertical flight with an average slope of 80.7 degrees and by the high values of intersection angles between individual stations, which is 89 degrees for the Ondřejov-Telč pair, 38 degrees for Ondřejov-Přimda and 53 degrees for Telč-Přimda. 
P. Spurný et al.: Reanalysis of the Benešov bolide

Table 1. Location of the cameras, their distances to the fireball beginning and end, and span of the recorded heights and total length.

\begin{tabular}{llllllllc}
\hline \hline \multirow{2}{*}{ Station } & \multirow{2}{*}{ Camera } & \multicolumn{2}{c}{ Coordinates (WGS84) } & \multicolumn{2}{c}{ Distance $(\mathrm{km})$} & \multicolumn{2}{c}{ Height $(\mathrm{km})$} & Recorded \\
& & longitude E & latitude N & Beg & End & Beg & End & length $(\mathrm{km})$ \\
\hline Telč & FE-F & 15.43843 & 49.15913 & 120.49 & 92.85 & 89.13 & 19.49 & 70.56 \\
Přimda & FE-F & 12.67790 & 49.66936 & 165.67 & 140.63 & 86.03 & 20.68 & 66.21 \\
Ondřejov & FE-F & 14.78137 & 49.90943 & 95.85 & 27.95 & 91.68 & 19.23 & 73.41 \\
Ondřejov & FE-G & 14.78137 & 49.90944 & 96.02 & 27.97 & 91.84 & 19.26 & 73.55 \\
Ondřejov & LF-S & 14.78169 & 49.90945 & 92.73 & 34.37 & 88.53 & $27.23^{a}$ & 62.11 \\
Ondřejov & LF-S & 14.78169 & 49.90945 & 81.79 & 28.26 & $77.47^{b}$ & 19.62 & 58.62 \\
\hline
\end{tabular}

Notes. FE-F means fish-eye-fixed camera, FE-G means fish-eye-guided camera, and LF-S means $360 \mathrm{~mm}$ spectral camera. ${ }^{(a)}$ Leaving field of view; ${ }^{(b)}$ entering field of view.

\section{Reanalysis of the atmospheric trajectory and comparison with the originally published data}

In February 2011, we completely reanalyzed the Benešov bolide with our new and significantly improved procedures (with respect to the procedures used in the $1990 \mathrm{~s}$ ).

First we scanned all available original all-sky glass plates $(9 \times 12 \mathrm{~cm})$ using the very precise photogrammetric scanner Vexcel UltraScan 5000. We extensively tested many different scanners in 2006-2007 and found that only this one is suitable for our task because the scanned copies do not exhibit any measurable distortion and loss of positional precision. Every all-sky image of the Benešov bolide was then scanned with the maximum resolution of 5 microns and 14 bit depth (file size $\sim 500 \mathrm{MB})$. Even though the image was scanned with a relatively high bit depth, the brightest parts of the luminous trajectory were still at least partly saturated on all images because of the extreme brightness of the bolide. For this reason this method is of only limited use for exact photometry. On the other hand, the positional measurement was easier with this method. Thanks to the many possibilities to adjust contrast and brightness of the scanned images during the measurement process, we were able to reliably measure positions of the trajectory and velocity points along the whole recorded luminous path of the bolide on all allsky images (except for the velocity from Ondřejov). This was the first noticeable difference in the trajectory determination because the original trajectory published in Spurný (1994) and Borovička \& Spurný (1996) was determined only from the parts of the bolide's luminous path that were clearly visible and adjustable. This means that only some points near the beginning and end, where the fireball was not overexposed, could be used in the original measurement. At this point it is necessary to emphasize that the original measuring method using the Ascorecord measuring device was in principle at least similarly precise and gave the same resolution as the new method. The only difference is that the measured points on the scanned copy are much easier to read and much better to adjust (with our own measuring software FishScan) than was possible with the binocular microscope in the Ascorecord measuring device.

Another important factor with noticeable influence on the trajectory determination were the imprecise coordinates of the camera sites, which were originally derived from topographic maps with the scale 1:25000 and given in the S42 coordinate system. In 1998 we remeasured all camera sites in our network with a professional GPS device, which provided an absolute precision of all camera positions better than $0.1 \mathrm{~m}$ in all three coordinates (longitude, latitude, altitude). When we converted these positions into the old coordinate system S42 and compared them with the original positions derived from maps, we found that they differ by about 10-20 $\mathrm{m}$ in longitude and latitude. This inaccuracy also contributed to the difference between new and original solution of the atmospheric trajectory.

The next, and still more important, difference lay in the different reduction methods of the all-sky images used in original and new analyses. In 1995 we invented the significantly improved reduction method for all-sky images as described in Borovička et al. (1995). Image orientation and especially object positions in larger zenith distances (larger than 70-75 degrees) are described much more precisely with this method. This was important for the Benešov case particularly for reducing the images from the more distant stations Přimda and Telč. The terminal part of the trajectory was relatively close to the horizon on both these stations because the bolide penetrated the atmosphere very deeply (deeper than $20 \mathrm{~km}$ ). It was 11.5 degrees above horizon on the Telč image and only 7.5 degrees for the Přimda image. This improved reduction approach was applied for the trajectory published in Borovička \& Spurný (1996), but the meteorite searches had been already discontinued at that time. Significantly more reference stars were measured in 2011 than in 1991, which also increased the precision and reliability of the reduced all-sky images: 65 for the Telč image (originally 42), 83 for the Ondřejov fixed all-sky image (originally 49) and 82 for Přimda image (originally 31 ).

The last and the most important difference in the atmospheric trajectory determination consisted in the originally undiscovered mistake made by the service at the station Telč. Because the cameras were operated manually at that time, the exact times of the beginning and end of the exposure with appropriate clock corrections were manually written into the exposure diary. Even in the early $90 \mathrm{~s}$ we used both beginnings and ends of the star trails for the image reduction, mainly to increase the number of positional stars. However, at that time, our computing software did not calculate the real length of the exposure from measuring the beginning and end points on the same star trail. We added this possibility with the graphical output several years later along with other improvements because we realized that the problem with the exposure time can occasionally occur, and it is possible to reveal it quite simply by this additional check. As we found several years after the original analysis in 1991, this problem certainly also occurred in the case of the Benešov bolide, namely for the Telč allsky image. In fact, even when we originally reduced this image, we found it difficult to get a reasonable common solution for the beginnings and ends of star trails. Originally we measured 13 beginnings and 29 ends on this image. This asymmetry was caused by the slightly better sky conditions at the end of the whole-night exposure. The significant excess of ends caused the reduction to be mainly based on the ends. The beginnings had larger standard deviations and seemed to be problematic. For that reason we finally decided to use only the ends of star trails for the reduction. 


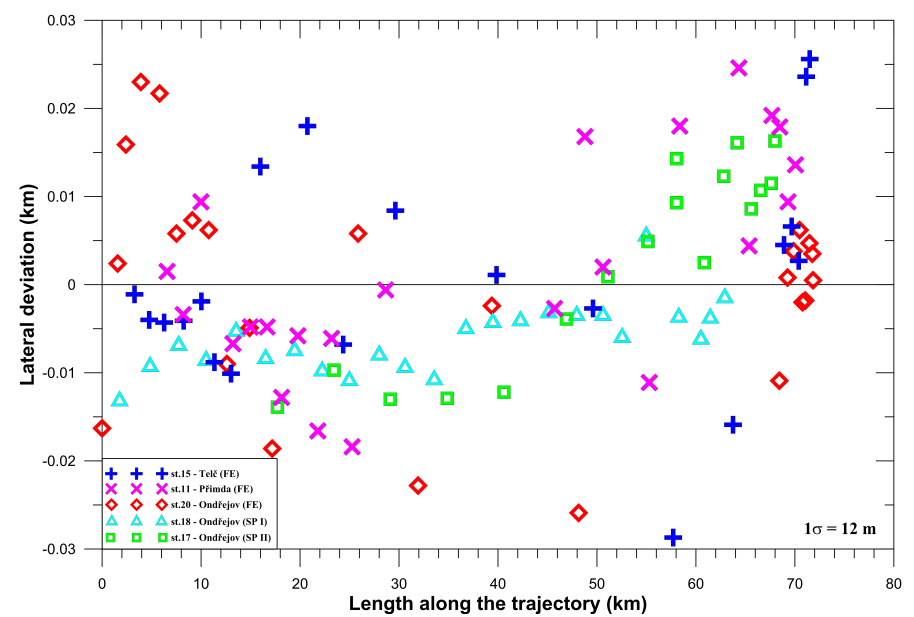

Fig. 2. Lateral deviations of all measured points on the luminous path of the fireball from all available records. Note that the $Y$-axis scale is highly enlarged and that one standard deviation for any point on the fireball trajectory is only $12 \mathrm{~m}$.

We also followed this train of thought during the reanalysis of the Benešov bolide published in Borovička \& Spurný (1996), where we computed the real length of exposure. We correctly found that the real length of this exposure was about $70 \mathrm{~s}$ shorter than recorded in the exposure diary, but unfortunately, we made the wrong assumption that the beginning time is in error and thus we shifted the beginning time $70 \mathrm{~s}$ ahead. For this reason the atmospheric trajectory published in Borovička \& Spurný (1996) is incorrect. However, it is important to mention that it is very difficult to pinpoint an error when only three stations are available. This task has no unambiguous solution, and we have to check all possibilities very carefully and compare quality and consistency of the given results from all possible aspects. It was practically impossible to identify the error when all the minor uncertainties contributed (camera positions, small number of measured trajectory points, old reduction methods, etc.). Originally we obtained a precision for the determination of the atmospheric trajectory position of about $50 \mathrm{~m}$ (one standard deviation). This was the standard precision of trajectory solutions we usually reached in that time.

Thanks to the increased internal precision, we were able to check all possible combinations and find the correct solution in 2011. The two main criteria were the following: 1) no systematic deviation of any record for all station solutions including long-focus spectral cameras, must be present; 2) the same velocity and deceleration profile must be obtained from all available records. The new solution is based on the beginnings of star trails on the Telč image. With this assumption and all improvements described above, all stations and records (including spectral records) fit with a standard deviation of only $12 \mathrm{~m}$ (Fig. 2).

The new and old solutions are compared in Fig. 3. The main difference is in the terminal part of the trajectory and in the position of the impact area. Other parts of the bolide analysis are affected only marginally or even negligibly. The new trajectory solution is shifted to the southwest by about $330 \mathrm{~m}$ (projection on the ground) at the end and only $90 \mathrm{~m}$ at the beginning (Figs. 3 and 4). Table 2 also lists the coordinates of the original and new solutions for beginning and terminal points taken for station Telč, where the same points were measured. From all these data it is evident that the main change between these two solutions is in the azimuth of flight, which is now shifted by about 1.3 degrees to the west. All basic atmospheric trajectory

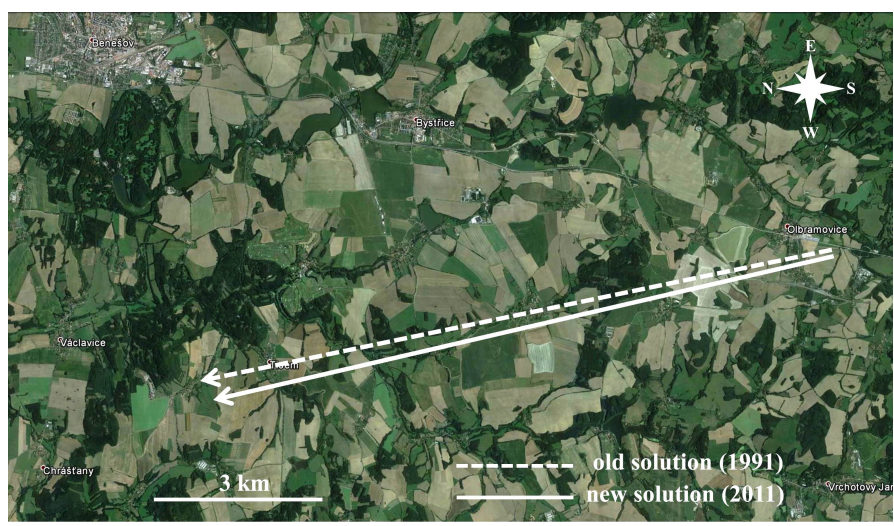

Fig. 3. Projection of the original trajectory solution (dashed line) and the new solution from 2011 (filled line). This includes all corrections discussed in Sect. 3. Both trajectories are given in the same WGS84 coordinate system (source of maps: Google Earth).

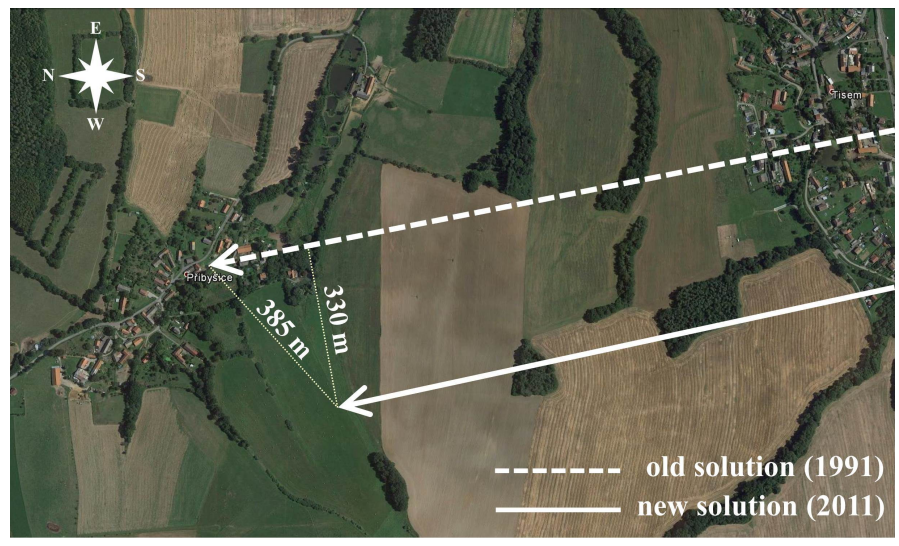

Fig. 4. Detail of the terminal part of the Benešov bolide, where the projection of the original trajectory solution (dashed line) is plotted along with the new solution from 2011(filled line). This includes all corrections discussed in Sect. 3. The shift between these two solutions is about $330 \mathrm{~m}$ westward (source of maps: Google Earth).

Table 2. Comparison of the reanalyzed and original (Spurný 1994) atmospheric trajectory position for the same measured beginning and terminal points on the station Telč.

\begin{tabular}{lcccc}
\hline \hline & \multicolumn{2}{c}{ Original data } & \multicolumn{2}{c}{ Reanalyzed data } \\
& beginning & end & beginning & end \\
\hline Height $(\mathrm{km})$ & 88.706 & 19.500 & 89.126 & 19.493 \\
Longitude $($ deg E) & 14.6349 & 14.6029 & 14.63393 & 14.59900 \\
Latitude $($ deg N) & 49.6663 & 49.7670 & 49.66578 & 49.76463 \\
Slope $($ deg) & 80.593 & 80.491 & 80.772 & 80.671 \\
Azimuth $(\mathrm{deg})$ & 348.377 & 348.353 & 347.109 & 347.083 \\
Total length $(\mathrm{km})$ & \multicolumn{2}{c}{70.160} & \multicolumn{2}{c}{70.555} \\
\hline
\end{tabular}

Notes. The two solutions are given for the same coordinate system WGS84. It corresponds to Figs. 3 and 4.

values resulting from the new corrected solution are listed in Table 3.

Here we also have to correct the original data of the terminal height of $16.7 \mathrm{~km}$ for the Ondřejov fixed image published in Spurný (1994) and Borovička \& Spurný (1996). We found that we were unable to reproduce the original measurement in this respect. This point was measured far from the last measured break and marked as uncertain in the original comments, therefore we decided to omit it. The real end of the bolide is the last measurable point just behind the end of the last break on the Ondřejov 
Table 3. Reanalyzed atmospheric trajectory data of the Benešov bolide.

\begin{tabular}{lccc}
\hline \hline & Beginning & $\begin{array}{c}\text { Maximum } \\
\text { brightness }\end{array}$ & Terminal \\
\hline Height $(\mathrm{km})$ & $91.675 \pm 0.002$ & 24.398 & $19.227 \pm 0.003$ \\
Longitude $($ deg E) & $14.63519 \pm 0.00003$ & 14.60149 & $14.59886 \pm 0.00006$ \\
Latitude $($ deg N) & $49.66220 \pm 0.00002$ & 49.75760 & $49.76502 \pm 0.00004$ \\
Slope $($ deg $)$ & $80.776 \pm 0.002$ & 80.678 & $80.671 \pm 0.002$ \\
Azimuth $(\mathrm{deg})$ & $347.110 \pm 0.014$ & 347.085 & $347.083 \pm 0.014$ \\
Total length $(\mathrm{km})$ & & 73.407 & \\
EN stations and cameras & 20 Ondřejov (2FE, 2LF-spectral), 15 Telč (FE), 11 Přrimda (FE) \\
\hline
\end{tabular}

Notes. Data for beginning and terminal points are taken from the record of the Ondřejov fixed all-sky camera.

fixed image, which lies at a height of $19.23 \mathrm{~km}$. This agrees well with other stations, as listed in Table 1.

These trajectory changes have virtually no influence on the dynamic solution (except for the small change of the initial velocity) and the fragmentation history of the event as described in Borovička \& Spurný (1996) and Borovička et al. (1998a), therefore we do not discuss this here. Similarly, it has no influence on the previously published analysis of the spectral records. On the other hand, small differences for the time of the bolide, the radiant position, and the initial velocity slightly changed the heliocentric orbit.

\section{Time of the bolide and heliocentric orbit}

In 1991 only one rigorous method for obtaining the time of the fireball passage from our records was available. We determined this time from combining the geometric solution of the atmospheric trajectory from all stations with the guided record of the fireball taken by the all-sky camera operated in a driven regime at Ondřejov observatory. However, because of the small changes to the trajectory solution, the time of the fireball passage was slightly shifted, exactly $7 \mathrm{~s}$ back. This small change now also better corresponds to most of the many visual observations. Unfortunately, most of them were rounded to whole minutes and thus not helpful in this respect, but a few of them are given in seconds and appear to be reliable. The new value of the time of the fireball passage valid for the middle of the recorded luminous trajectory is $23^{\mathrm{h}} 03^{\mathrm{m}} 46^{\mathrm{s}}$ UT, with an uncertainty of about $2 \mathrm{~s}$. Likewise, the radiant position was affected because of small changes of the direction of flight of the Benešov bolide, as described in Sect. 3. The new solution also caused a lengthening of the trajectory (see Table 2), which in turn increased the value of the initial velocity determined by the method described in Ceplecha et al. (1993) to $21.256 \mathrm{~km} \mathrm{~s}^{-1}$. These small changes of the input parameters resulted in the new revised orbit, computed by the standard method described in Ceplecha (1987), which is given in Table 4 and plotted in Fig. 5. This is of course slightly different from the orbit published in Spurný (1994) and Borovička \& Spurný (1996). The preatmospheric orbit of the Benešov meteoroid is one of the most precise orbits for known meteorite falls.

\section{Revised scenario of the fireball event and the impact area formation}

Although the shift of the new trajectory with respect to the old one does not seem to be too large, in reality it is large enough to explain why we did not find any meteorite despite great efforts
Table 4. Revised radiant and orbital elements (J2000.0) of the Benešov meteorite fall.

\begin{tabular}{cc}
\hline \hline Time $(\mathrm{UT})$ & $23^{\mathrm{h}} 03^{\mathrm{m}} 46^{\mathrm{s}} \pm 2^{\mathrm{s}}$ \\
\hline$\alpha_{R}(\mathrm{deg})$ & $228.635 \pm 0.009$ \\
$\delta_{R}(\mathrm{deg})$ & $40.606 \pm 0.002$ \\
$v_{\infty}\left(\mathrm{km} \mathrm{s}^{-1}\right)$ & $21.256 \pm 0.005$ \\
$\alpha_{G}(\mathrm{deg})$ & $227.617 \pm 0.010$ \\
$\delta_{G}(\mathrm{deg})$ & $39.909 \pm 0.002$ \\
$v_{G}\left(\mathrm{~km} \mathrm{~s}^{-1}\right)$ & $18.081 \pm 0.006$ \\
$v_{H}\left(\mathrm{~km} \mathrm{~s}^{-1}\right)$ & $37.427 \pm 0.004$ \\
$a(\mathrm{AU})$ & $2.483 \pm 0.002$ \\
$e$ & $0.6274 \pm 0.0004$ \\
$q(\mathrm{AU})$ & $0.92515 \pm 0.00002$ \\
$Q(\mathrm{AU})$ & $4.040 \pm 0.005$ \\
$\omega(\mathrm{deg})$ & $218.370 \pm 0.008$ \\
$\Omega(\mathrm{deg})$ & 47.001 \\
$i(\mathrm{deg})$ & $23.981 \pm 0.007$ \\
$P($ years $)$ & $3.912 \pm 0.005$ \\
\hline
\end{tabular}

Notes. Time is given for the middle of the recorded luminous trajectory.

Table 5. Points defining the most likely impact line for larger pieces.

\begin{tabular}{lcc}
\hline \hline $\begin{array}{l}\text { Mass } \\
(\mathrm{kg})\end{array}$ & \multicolumn{2}{c}{ Coordinates } \\
longitude E & latitude N \\
\hline 1.25 & 14.6074 & 49.7775 \\
1.00 & 14.6083 & 49.7769 \\
0.75 & 14.6093 & 49.7763 \\
0.50 & 14.6108 & 49.7754 \\
0.25 & 14.6135 & 49.7740 \\
0.10 & 14.6174 & 49.7725 \\
\hline
\end{tabular}

Notes. In reality, meteorites can be found up to $200 \mathrm{~m}$ around this line and the masses can be partially mixed (because of different shapes, terminal heights, side motions, etc.).

and many attempts in the weeks and years after the fall. The reason is that we focused only on the area where large pieces were expected. That area only partly overlapped with the similarly large area determined from the new computations. The points defining the most probable line for larger pieces according to the new computation are given in Table 5. From the analysis of the spectral records taken by the long-focus $360 \mathrm{~mm}$ cameras we knew that at least eight fragments (including the main piece) with terminal masses on the order of hundreds of grams (up to about 1-2 kg, which could be the mass of the main piece) could reach the ground (see the Fig. 4 and Table 2 in Borovička \& Spurný 1996). Originally, we were able to relatively reliably search a strip about $400-500 \mathrm{~m}$ wide at most and about $1 \mathrm{~km}$ long 


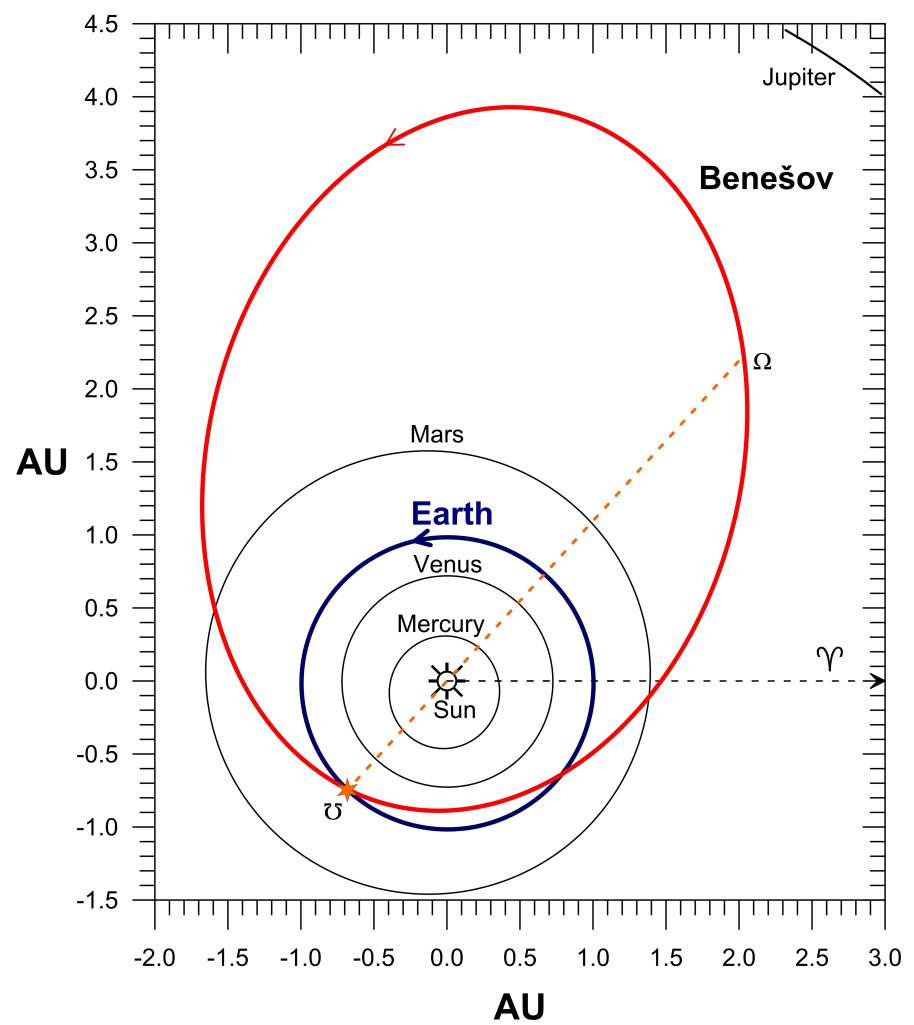

Fig. 5. Heliocentric orbit of the Benešov meteoroid projected onto the plane of the ecliptic along with the orbits of all inner planets and Jupiter and the direction to the vernal equinoctial point.

that covered the entire predicted area for the hundred gram to kilogram mass range. However, this area covered only about half of the area computed from the new atmospheric trajectory solution. The area (both new and old) is very difficult to search because of the rugged terrain that is partly covered by mixed forest of different age and partly by bushes. Finally we concluded that this was the main reason for missing the meteorites, although it seemed to be rather strange that we did not find any meteorite, at least from the eight largest pieces observed. On the other hand, when we saw this area in 2011, we realized that it is practically impossible to reliably search there because apart from the very difficult terrain, the area significantly changed during the past 20 years. This change was caused both by natural processes (new layers of leaves and needles, some parts of surface changed by wild animals, mainly wild pigs) and also by human activities. Even apart from standard farming, a substantial part of the original forest was chopped down and planted again. Together with the expected significant change of the meteorite appearance after this time, when the parts certainly would have lost fresh fusion crust and very probably look like numerous regular stones, we realized that it is not possible to efficiently search this new area for the larger pieces. We only reconnoitred this area and briefly searched it.

Clearly, we had to find another way to search for meteorites more efficiently and with some real chance of success. In this sense, we gathered great experience from the instrumentally observed Košice meteorite fall on 28 February 2010, which we analyzed in detail (Borovička et al. 2013a) before reanalyzing the Benešov bolide. This large event of the superbolide category produced many meteorites of different sizes from subgram to a few kilograms, and more than 200 pieces with a total mass of about $11 \mathrm{~kg}$ were found in the predicted impact

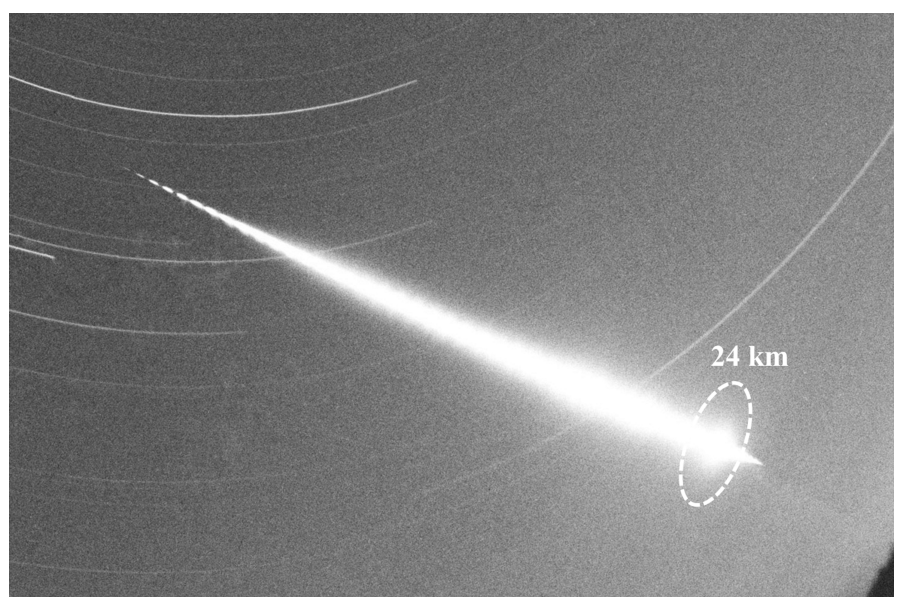

Fig. 6. Detail of the Benešov bolide recorded by the fixed all-sky camera at Telč station showing the main terminal flare at a height of $24 \mathrm{~km}$ from where a cloud of small fragments originated.

area. The Košice bolide was in many aspects similar to the Benešov bolide. Both were similarly large bodies with diameters between 1 and $2 \mathrm{~m}$, masses of about 4 tons (the best estimate for Benešov is $4100 \mathrm{~kg}$ (Ceplecha \& ReVelle 2005) and for Košice it is $3500 \mathrm{~kg}$ (Borovička et al. 2013a)), both belong in the superbolide category (Benešov was about 1 mag brighter because its initial velocity was higher by about $6 \mathrm{~km} \mathrm{~s}^{-1}$ ), and both had undergone severe (cascade) fragmentation that created a whole spectrum of meteorite sizes. However, there were three important differences in favor of Benešov. First, we had much better records of the bolide, which enabled us to determine the trajectory, dynamics, and possible impact area with much higher precision than for the Košice fall, where only three casual video records of lower quality were available. The second difference was in the slope of the trajectory. Although both bolides had relatively steep trajectories, the Benešov atmospheric flight was about 20 degrees steeper and almost vertical (only 9 degrees from vertical flight). The third important difference was that more mass penetrated to a deeper atmosphere (heights about $25 \mathrm{~km}$ ) in the case of the Benešov bolide. Unfortunately, we only have a low-resolution photographic light curve for the Benešov bolide (Borovička \& Spurný 1996) and no such detailed light curve as for Košice (Borovička et al. 2013a). This was detected by fast photometers of the autonomous fireball observatories in the Czech fireball network (Spurný et al. 2006), which enabled us to model the cascade fragmentation for the Košice fall. However, from the photographic records we know that in the case of Benešov there was one distinct huge flare at $24.4 \mathrm{~km}$ altitude. It is clearly visible in Fig. 6, where we show a detailed view of the fireball recorded by the fixed all-sky camera at Telc station. In a scenario similar to the Košice fall, a huge number of small fragments was created during this severe fragmentation (according to Borovička et al. 1998a about $800-1000 \mathrm{~kg}$ of total mass suffered this last fragmentation) most of which reached the ground. Because of this one distinct fragmentation event and almost vertical flight, a relatively small impact area had to be sprayed by thousands of small meteorites, similarly as we predicted in the Košice case, where this was at least partly confirmed by the real finds. However, because in the case of Benešov it was from a much lower altitude and from a much steeper trajectory, the area of these small pieces was probably on a much smaller territory. We were sure that with the experience we now have we would very probably find at least some of these small 


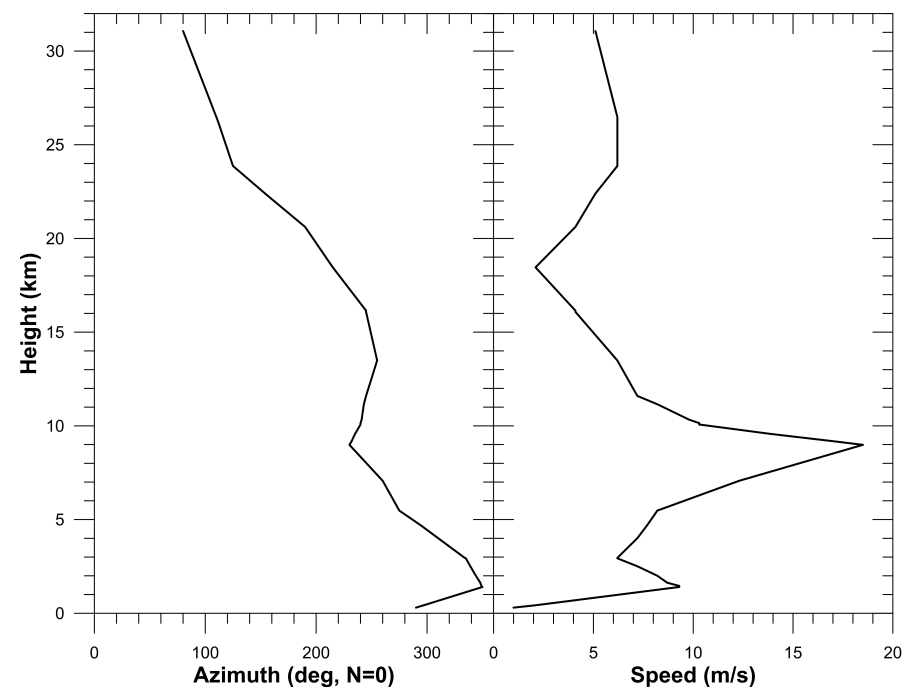

Fig. 7. Vertical profile of atmospheric wind for azimuth (left) and speed (right). Data are taken from balloon measurements from Prague on May 8 at 0 UT, which is very close both geographically and temporally to the place and time of the Benešov bolide (source: University of Wyoming, http://weather.uwyo.edu/upperair/ sounding.html).

meteorites even though we would search in a slightly different area (shifted by about $300 \mathrm{~m}$ eastward). Unfortunately, we did not take this possibility into account in the weeks and years after the fall, and we did not make any attempt to search in this small gram-size meteorites area. The main reason was that in that time it was believed that such huge flares produce only a large cloud of small dust-sized particles except for a few larger pieces. These small particles are very quickly radiated in this one very huge flare. Later it was found, however, (as described, for example, for the Košice fall in Borovička et al. 2013a and for Chelyabinsk in Borovička et al. 2013b) that this scenario cannot explain the long duration of this sort of flare that was also observed in the Benešov case. The long duration can only be explained when there are many pieces with sizes of a few grams to tens of grams in addition to dust-sized particles. These small pieces can be very quickly decelerated, and many of them can survive such catastrophic disruption and land on the ground. Indeed, when modeling the profile of the Benešov terminal flare in a similar way as for Košice, we found that the flare was probably caused mostly by fragments in the $1-10 \mathrm{~g}$ range. There were about $250000 \mathrm{of}$ these fragments, while 40000 of them were probably larger than $5 \mathrm{~g}$. This was the scenario we decided to apply for Benešov and to verify 20 years after the event by a search in the predicted area.

\section{Dark-flight modeling and the location of the revised impact area}

Taking into account this scenario of many small pieces that might have reached the ground from the huge flare at a height of $24.4 \mathrm{~km}$, we computed the most probable landing area for meteorites of 5-10 g sized meteorites using the dark-flight procedure described in Ceplecha (1987). This was the mass range we primarily focused on because we assumed that a very many such pieces were created there and that pieces of this size might still be found, as we realized from the Košice search. Fortunately, we were able to obtain more detailed information about the wind

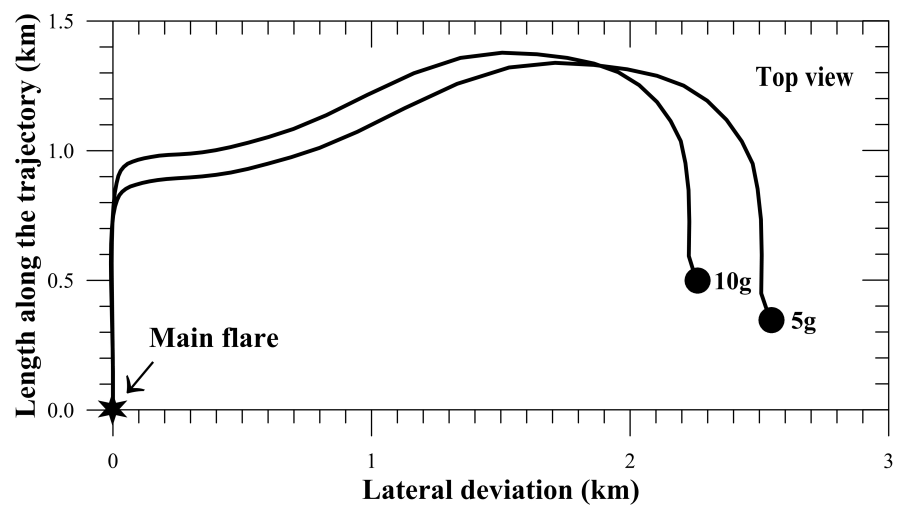

Fig. 8. Simulation of the dark-flight for the gram-sized meteorites that originated in the main flare at $24 \mathrm{~km}$. The dark-flight for these small meteorites lasts about $7 \mathrm{~min}$.

profile (taken from the University of Wyoming ${ }^{1}$ ) than we originally obtained from the Czech meteorological service in 1991. As shown in Fig. 7, these new data covered the whole range of altitudes starting from $31 \mathrm{~km}$, covering the main flare and continuing to the ground. This dataset consists of 31 distinct measurements instead of the 11 measurements we used in 1991. However, this better wind data coverage has no significant influence on the impact area position because both datasets have the same source (Prague radiosonde at 0 UT), which means that the numbers are the same and the range of altitudes with the strongest wind is covered similarly. The strongest wind was blowing between heights of $12-5 \mathrm{~km}$ from SW-W and it shifted the impact area for the small pieces by about $2.5 \mathrm{~km}$ to ENE. This is schematically shown in Fig. 8, where dark-flight trajectories for the 5- and 10-g meteorites are plotted from a top-view perspective. The dark-flight for these small meteorites lasted for about $7 \mathrm{~min}$. When we projected this result of the dark-flight modeling on the map we found that this new impact area of small meteorites that originated from the main flare at $24.4 \mathrm{~km}$ lies inside a large and clearly arranged field. This situation is shown in Fig. 9, where the end of the new trajectory of the fireball with marked position of the main flare and corresponding impact area for small pieces that originated in this flare are projected on the map. The large and favorable difference of this area compared with the terrain of the larger pieces area is evident. This enabled us to search in a very well arranged field with a nicely smooth surface. On the other hand, it also meant that this area was changed at least 20 times because this field has been regularly cultivated every year. Because it is used solely for crop farming, this field is ploughed, planted and harvested each year. This means that after 20 years of such intensive agricultural activity the original meteorites have been uniformly mixed in the $30-40 \mathrm{~cm}$ thick layer of soil because of deep ploughing. However, assuming that very many pieces formed in a dense cloud that covered a relatively small area, some meteorites should still be present close to the surface. The meteorites remained for 20 years in a wet soil during the changing seasons, with frozen earth up to $30 \mathrm{~cm}$ deep in winter. Together with the intensive agricultural activity, this would have gradually fragmented and crumbled the small meteorites into even smaller pieces. Moreover, these progressive weathering processes would also have smoothed all typical meteorite features (fusion crust, rounded shapes) therefore it was not possible to search for them visually. This was additionally complicated because this territory

http://weather. uwyo.edu/upperair/sounding.html 


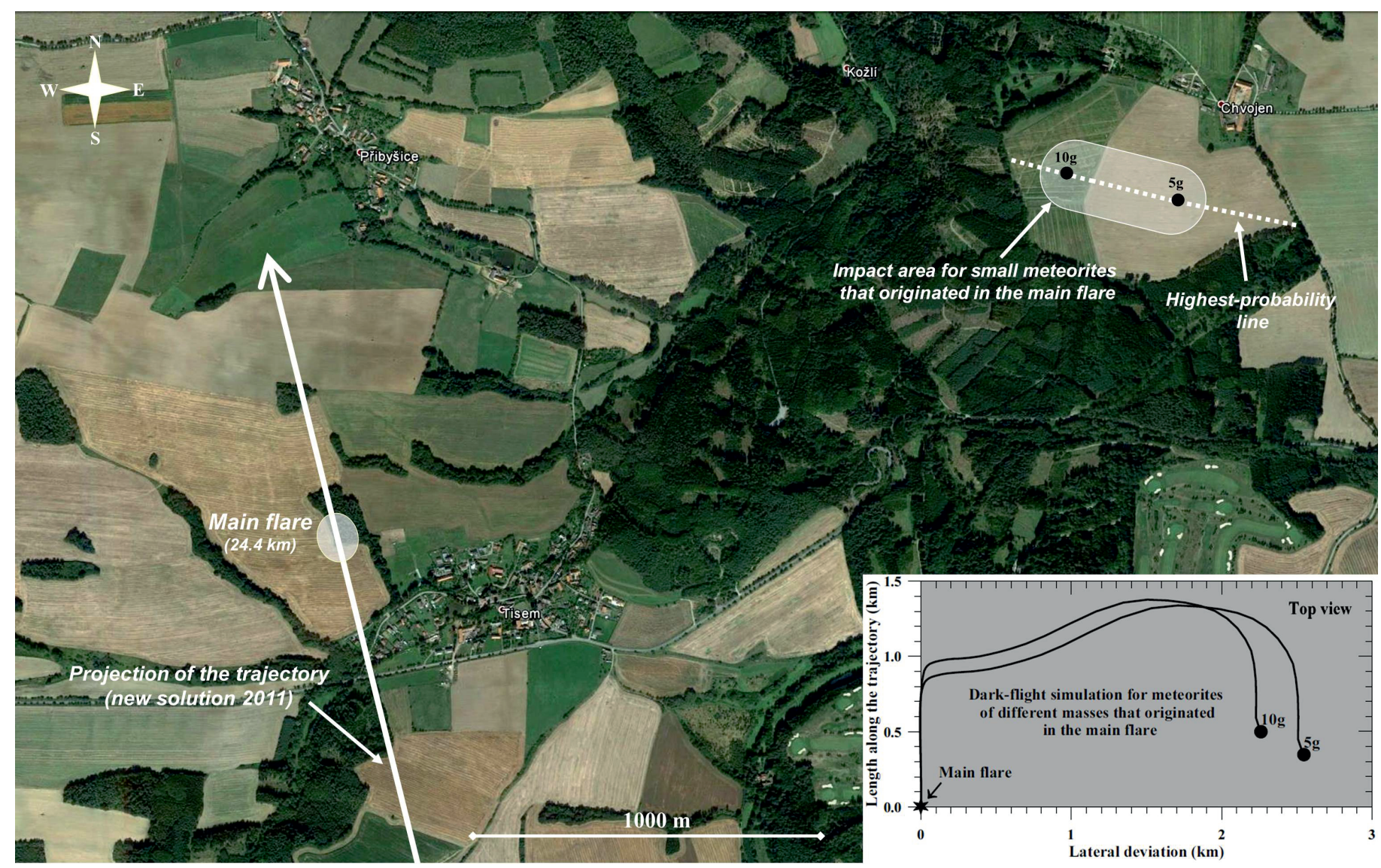

Fig. 9. New trajectory of the fireball with marked position of the main flare and the corresponding impact area for small pieces that originated in this flare (source of maps: Google Earth).

has been settled for more than one thousand years, which means that there are many artifacts of human activity connected mainly with agriculture and some mining activities (silver) especially in the medieval age. This made it impossible to expect that we would find a meteorite just by walking in the area and searching the surface. We had to find some other way to distinguish meteorites from regular terrestrial stones, slag, and various oxidized iron pieces, everything coated by soil.

Fortunately, we have very important information about the probable composition of the Benešov meteoroid from our spectral records. As mentioned, the Benešov bolide was recorded by two long-focus spectral cameras from Ondřejov observatory, and as shown in Table 1, these very detailed records covered the whole atmospheric flight of the bolide. The detailed analysis of these unique spectra was published in several papers by Borovička \& Spurný (1996) and Borovička et al. (1998b), and one of the published results is that the bulk composition of the Benešov meteoroid was chondritic. This means that the meteorites probably contain a relatively high proportion of iron and that these samples might be detectable by metal detectors. This was what we decided to use for searching. First we tested several types of detectors and selected those that reacted to ordinary chondrite meteorites. For this purpose the Košice fall helped us again because one small $16 \mathrm{~g}$ meteorite found during the searching campaign in the Košice impact area at the end of March 2010, which we originally used for the classification, remained with us and thus we could calibrate detectors on a real meteorite each time we searched in the field.

\section{Search strategy and meteorite finds}

Everything was prepared for a search at the beginning of April 2011. This was timely, since the field had just been sown with wheat at the end of March and it started to grow quickly in the wet soil. We realized later that we were very lucky with this perfect arrangement of the search area (the field was perfectly flat without any cover and clods and the soil was uniformly and appropriately wet) because although we tried to repeat the search in the next weeks and years, the area was never in such perfect conditions as for this first search period at the beginning of April 2011. Our search strategy was focused close to the line of the highest probability and we tried to cover as large a part as possible of the area marked in Fig. 9. We also made several transverse scans a few hundred meters long and about $15 \mathrm{~m}$ wide, which also covered parts of the field outside the predicted area.

The first and the most intensive search took place on 9 April 2011, when a large group of about 20 searchers (most of them were experienced treasure hunters led by Mlejnský) equipped with suitable metal detectors searched several hours in the predicted area and covered a large part of it. Several tens of samples were collected for detailed inspection. Like for the similar activities later, each collected piece was documented, that is, we labeled and weighed it, took its GPS position and its picture. After the field work we washed and cleaned each collected sample and selected further. Only eight samples passed this selection. They were weighed and photographed again and then inspected in much more detail by one of us $(\mathrm{JH})$ in the 


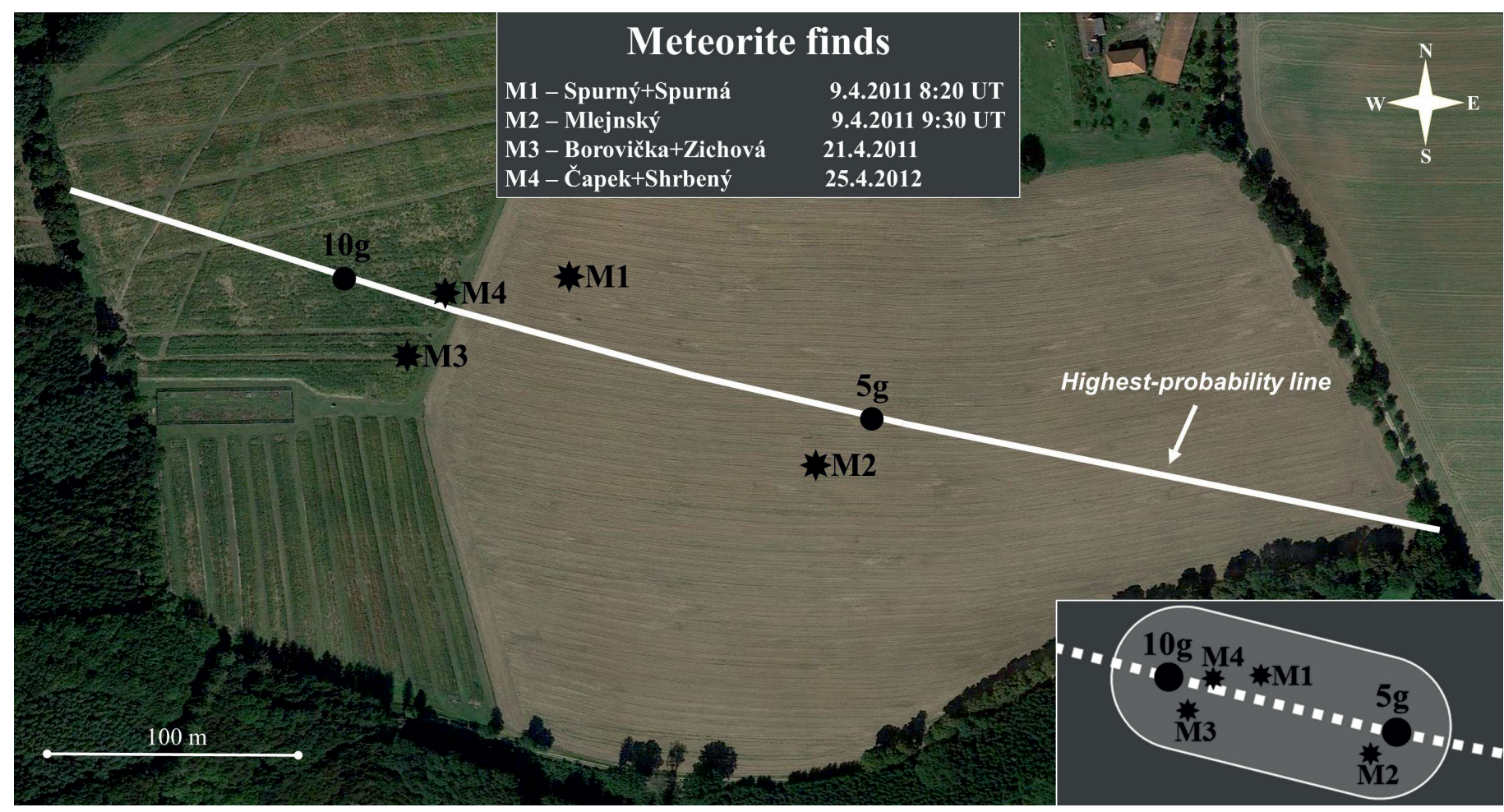

Fig. 10. Details on meteorite finds and their positions with respect to the predicted impact line and impact area as marked in Fig. 9 (source of maps: Google Earth).

Table 6. Details of the recovered meteorites.

\begin{tabular}{|c|c|c|c|c|c|c|c|}
\hline \multirow{2}{*}{$\begin{array}{l}\text { Met. } \\
\text { No. }\end{array}$} & \multirow{2}{*}{$\begin{array}{l}\text { Date of } \\
\text { find }\end{array}$} & \multirow{2}{*}{$\begin{array}{l}W 1 \\
(\mathrm{~g})\end{array}$} & \multirow{2}{*}{$\begin{array}{l}W 2 \\
(\mathrm{~g})\end{array}$} & \multirow{2}{*}{$\begin{array}{l}\text { Meteorite } \\
\text { type }\end{array}$} & \multicolumn{2}{|c|}{ Coordinates } & \multirow{2}{*}{ Finders } \\
\hline & & & & & longitude E & latitude $\mathrm{N}$ & \\
\hline$\overline{\mathrm{M} 1}$ & 9.4 .2011 & 2.91 & 1.54 & $\mathrm{H} 5$ & 14.6325 & 49.7665 & Spurný, Spurná \\
\hline M2 & 9.4 .2011 & 12.93 & 7.72 & LL3.5 + PA & 14.6345 & 49.7655 & Mlejnský \\
\hline M3 & 21.4 .2011 & 2.29 & 1.99 & LL3.5 & 14.6311 & 49.7661 & Borovička, Zichová \\
\hline M4 & 25.4.2012 & 0.50 & 0.38 & LL3.5? & 14.6315 & 49.7664 & Čapek, Shrbený \\
\hline
\end{tabular}

Notes. $W 1$ means the original weight of the sample after the find, $W 2$ is the final mass of meteorite after cleaning and brushing. PA is short for primitive achondrite. The classification of the smallest piece M4 is uncertain because of high weathering grade.

laboratory on 15 April 2011. Each sample was cleaned by ultrasound washer, had part of its surface brushed, and had its interior examined in the microscope. The result surpassed all our expectations: two samples proved to be real meteorites (designated M1 and M2). Another very exciting result of this first inspection was that at first sight the structures of these samples differed significantly. While chondrules are nicely visible in the larger $8 \mathrm{~g}$ sample, the smaller sample weighing only $1.5 \mathrm{~g}$ (after cleaning and brushing) did not show any similar features. This was confirmed four days later when these two meteorites were examined with an electron microscope and both meteorites were classified (described in detail in the next section). After this great success we continued searching in the predicted area until mid-May. However, the situation in the main part of the field where wheat was planted changed very quickly (growth was too high and dense) and made a search by metal detectors impossible. Only the western part of the field (about a quarter of the predicted area) was still not covered by vegetation because it was prepared for later corn sowing and thus we could search only there. However, the surface of this field was not so flat because of larger clods, which complicated the use of metal detectors. The limited sensitivity of the detectors meant that they had to be as close as possible to the surface. In combination with the fact that the surface soil dried very fast because of warm weather the metal detectors were much less efficient than during the first search attempt. For these reasons only one additional sample found on 21 April was classified as a meteorite (M3). In the autumn, the search conditions were not favorable for metal detectors at all because the field was deeply ploughed and was sown just before winter with oilseed rape, which very quickly covered it. It also made all search activities in this area inefficient during the next year. We tried to search in the small part of the western field using a different way: we took all stones from one square meter (we sieved soil from the upper $10 \mathrm{~cm}$ ) close to the most probable line where we could search this way and selected auspicious samples from it. This way, one very small (half a gram) meteorite (M4) was found on 25 April 2012.

Altogether, we found four meteorites with a total weight (after cleaning and brushing) of $11.63 \mathrm{~g}$ (Fig. 10). Details of them (positions, weights, finders) are collected in Table 6, and the first three of them are shown in Fig. 11. We have to note here that any search activities in this area were possible only with the approval of the field owner, and it is strictly prohibited to search there without this permission. 


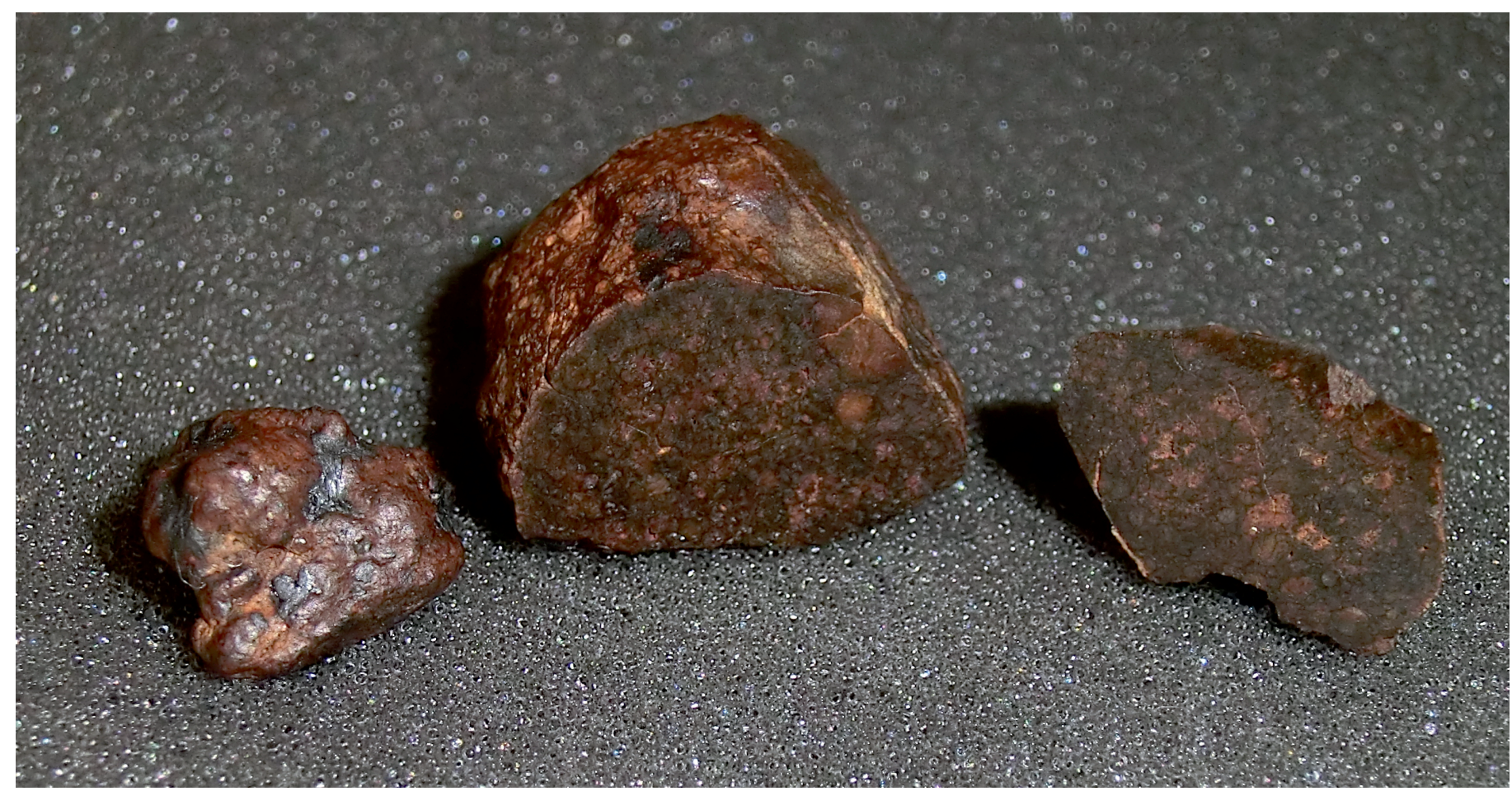

Fig. 11. First three Benešov meteorites found by metal detectors in April 2011. From left to right: $1.56 \mathrm{~g} \mathrm{H5}$ chondrite (designed in Fig. 10 as M1), 7.72 g LL3.5 chondrite with achondrite clast (M2), and $1.99 \mathrm{~g}$ LL3.5 chondrite (M3).

\section{Petrography and mineral chemical composition}

The first three Benešov meteorites (M1-M3) found in April 2011 were used to study their petrography, mineralogy, and microchemical composition. A polished thick section was prepared from each meteorite. For this, each meteorite fragment was embedded in a resoluble Technovit 5071 resin, polished by using a set of grinding and polishing pastes. For the final polishing Struers OPU colloidal silica suspension was used. Finally, all prepared thick sections were coated by a $30 \mathrm{~nm}$ thick conductive layer of carbon for the purposes of microanalytical studies. Very small fragments of the meteorites obtained during grinding were also used to prepare thin sections to study optical features with the LEICA DLMP petrographic microscope.

The scanning electron microscope TESCAN MIRA 3GMU (Czech Geological Survey in Prague, Czech Republic) was used for all microanalytical studies and collection of backscattered electron images. Mineral compositions were determined using the Oxford Instruments AZtec Energy Automated analytical system with an SDD X-ray energy dispersive detector X-MaxN 80 Premium (EDS) and the X-ray wavelength dispersive detector Wave 500 (WDS). Both analytical systems installed on the mentioned scanning electron microscope TESCAN MIRA 3GMU were used for simultaneous EDS-WDS analysis. Analyses were performed using an accelerating voltage of $15 \mathrm{kV}, 20 \mathrm{nA}$ beam current, $0.170 \mu \mathrm{m}$ beam size, and XPP matrix correction procedures. Acquisition live time for analysis of major elements by EDS was $60 \mathrm{~s}$ and output countrate $110 \mathrm{kcps}$. Counting times for analysis of minor and trace elements by WDS system were 15,20 or $30 \mathrm{~s}$. To avoid $\mathrm{Na}$ and $\mathrm{K}$ ions migration during the analysis of glass and maskelynite present, the beam diameter was enlarged to $5 \mu \mathrm{m}$. For simultaneous EDS-WDS analysis a combination of natural and synthetic standards was used for standardization and calibration process.
The integrated electron backscattered diffraction system (EBSD) Oxford Instruments AZtec HKL Automated and Nordlys Nano detector, installed on the scanning electron microscope was used to confirm the microstructural characteristics of the minerals. The analytical conditions were $15 \mathrm{~mm}$ working distance, $20 \mathrm{kV}$ accelerating voltage, and $3.5 \mathrm{nA}$ beam current.

\section{Benešov (a)}

Meteorites M2 and M3 (7.72 g and $1.99 \mathrm{~g}$ ) were designed officially as Benešov (a) meteorites. Both meteorite fragments lacked a fusion crust and were strongly weathered from 20 years of residence in the strewn field. The meteorite is a polymict breccia containing two recognized lithologies with a completely different texture and chemical and mineralogical composition.

The largest portion of the M2 meteorite is represented by an LL3.5 chondrite (average olivine and low-Ca pyroxene composition $\mathrm{Fa}_{28.2}, \mathrm{Fs}_{23.7}$ ). This lithology consists of very well defined chondrules and fine grained matrix (see Fig. 12). Silicate minerals are represented mainly by olivine, low-Ca pyroxene, plagioclase and predominantly weathered alcalic glass. The Fe-Ni phases and troilite are almost completely weathered and many of their weathering products are presented (see Fig. 12). The chondrules and matrix are unequilibrated. Chondrules $(0.2-1.9 \mathrm{~mm})$ consist mostly of olivine $\left(\mathrm{Fa}_{6-35}\right)$, low-Ca pyroxene $\left(\mathrm{Fs}_{1-37}, \mathrm{Wo}_{0.7-3}\right)$, and alkali-bearing glass exhibiting a wide range of chemical compositions, which is a typical feature of meteorites that are significantly unaffected by thermal metamorphism processes. The olivine in the chondrules contains on average $0.08 \mathrm{wt} \% \mathrm{Cr}_{2} \mathrm{O}_{3}$. Type I chondrules contain 0.17 to $1.1 \mathrm{wt} \% \mathrm{CaO}$ and Type II 0.04 to $1.1 \mathrm{wt} \%$. The fine-grained matrix contains olivine $\left(\mathrm{Fa}_{20-41}\right)$, low-Ca pyroxene $\left(\mathrm{Fs}_{1-32}, \mathrm{Wo}_{0.7-3.5}\right)$, predominately weathered alkalic glass, $\mathrm{Fe}-\mathrm{Ni}$ phases, and troilite. 



Fig. 12. Backscattered electron images documenting the texture of the LL3.5 lithology of meteorites M3 (left) and M2 (right) - designated as Benešov (a). Well-defined chondrules and fine-grained matrix are disrupted by a network of microfractures filled by weathering products.

Olivine, pyroxene, and plagioclase in this LL3.5 lithology show weak shock features represented by observed sets of planar fractures in olivine, undulose extinction of olivine grains, and very thin melt veins corresponding to shock stage S3. The collected EBSD patterns from plagioclase confirmed that no evidence for a phase change of plagioclase to maskelynite glass was found. This supports that the observed optical features of the minerals and the estimated shock pressures are in a range of 15-20 GPa according to the classification described by Stöeffler et al. (1991). The two studied fragments are affected by strong weathering, represented mostly by heavy oxidation of Fe-Ni phases and troilite (around 95\% replaced by oxidation products). The weathering products also fill a network of thin microfractures and cracks throughout the samples (see Fig. 12). These observed weathering features indicate weathering grade W3 according to the classification of Wlotzka (1993).

Within a thick section of the M2 Benešov (a) fragment, the adjacent achondritic lithology was found as a clast $(4.8 \times 2.6 \mathrm{~mm})$ cemented to the LL3.5 chondrite lithology by an irregular vein of impact melt (see Fig. 13). This achondritic clast is composed predominantly of olivine ( $\left.\mathrm{Fo}_{90-69}\right)$ and low-Ca pyroxene $\left(\mathrm{En}_{79-62}, \mathrm{Wo}_{1.2-4.8}\right)$. Anorthitic plagioclase $\left(\mathrm{An}_{86-81}, \mathrm{Ab}_{18-14}\right)$ and high-Ca pyroxene $\left(\mathrm{En}_{56-48}, \mathrm{Wo}_{43-32}\right)$ are also present. The achondritic clast texture and mineral chemistry indicate that the clast probably originated by crystallization from chondritic impact melt. However, the relation to surrounding LL3.5 lithology is obviously defined by impact processes within the parent body; the brecciated character of this meteorite was the result. The achondritic clast shows features corresponding to a slightly higher shock stage S4 represented by olivine mosaicism and the plagioclase partial phase change to maskelynite glass, as confirmed by EBSD data.

\section{Benešov (b)}

The meteorite M1 (1.54 g fragment) found at the strewn field was classified as H5 chondrite (average olivine and low-Ca pyroxene composition $\mathrm{Fa}_{19.1}, \mathrm{Fs}_{17.1}$ ) with the official name Benešov (b). As for Benešov (a), the fragment is strongly weathered and has no fusion crust. The present chondrules are weakly preserved and mostly recrystallized by the effect of thermal metamorphism (see Fig. 14). The mineral chemical composition is also almost equilibrated. This $\mathrm{H} 5$ lithology contains olivine $\left(\mathrm{Fa}_{17.8-20.2}\right)$, low-Ca pyroxene $\left(\mathrm{Fs}_{15.7-18.7}, \mathrm{Wo}_{0.7-1.5}\right)$, plagioclase $\left(\mathrm{Ab}_{77-86}\right.$, $\mathrm{An}_{12-19}$, grain size $\left.6-40 \mu \mathrm{m}\right)$, and high-Ca pyroxene $\left(\mathrm{Fs}_{6.2-9}\right.$,

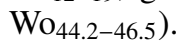

Olivine, pyroxene, and plagioclase in the H5 lithology show shock features represented by sets of planar fractures in olivine, undulose extinction of olivine grains and several thin melt veins corresponding to shock stage S3. As for Benešov (a), the collected EBSD patterns from plagioclase confirmed that there is no evidence of a phase change of plagioclase to maskelynite glass. The fragment is strongly weathered, and about $80 \%$ of the $\mathrm{Fe}-\mathrm{Ni}$ phases and troilite are replaced by oxidation products (see Fig. 14). The obvious network of microfractures completely filled by weathering products was also documented. These weathering features indicate weathering grade W3. Unfortunately, any other lithologies within this fragment were not observed, and therefore the relation to Benešov (a) lithology is unclear. However, the brecciated character of Benešov (a) strongly supports our opinion that Benešov (b) is only additional lithology of the same complicated and brecciated parent body of the Benešov meteorites.

Note that we originally suggested the same name Benešov for all the meteorites described here but it was not accepted by the Nomenclature Committee of the Meteoritical Society.

\section{Discussion}

In very rare cases, meteorites are seen to fall just after a bolide observation, as for example in the case of the Morávka meteorite fall (Borovička et al. 2003). Then we have direct evidence that the recovered meteorites are connected with the observed bolide. 

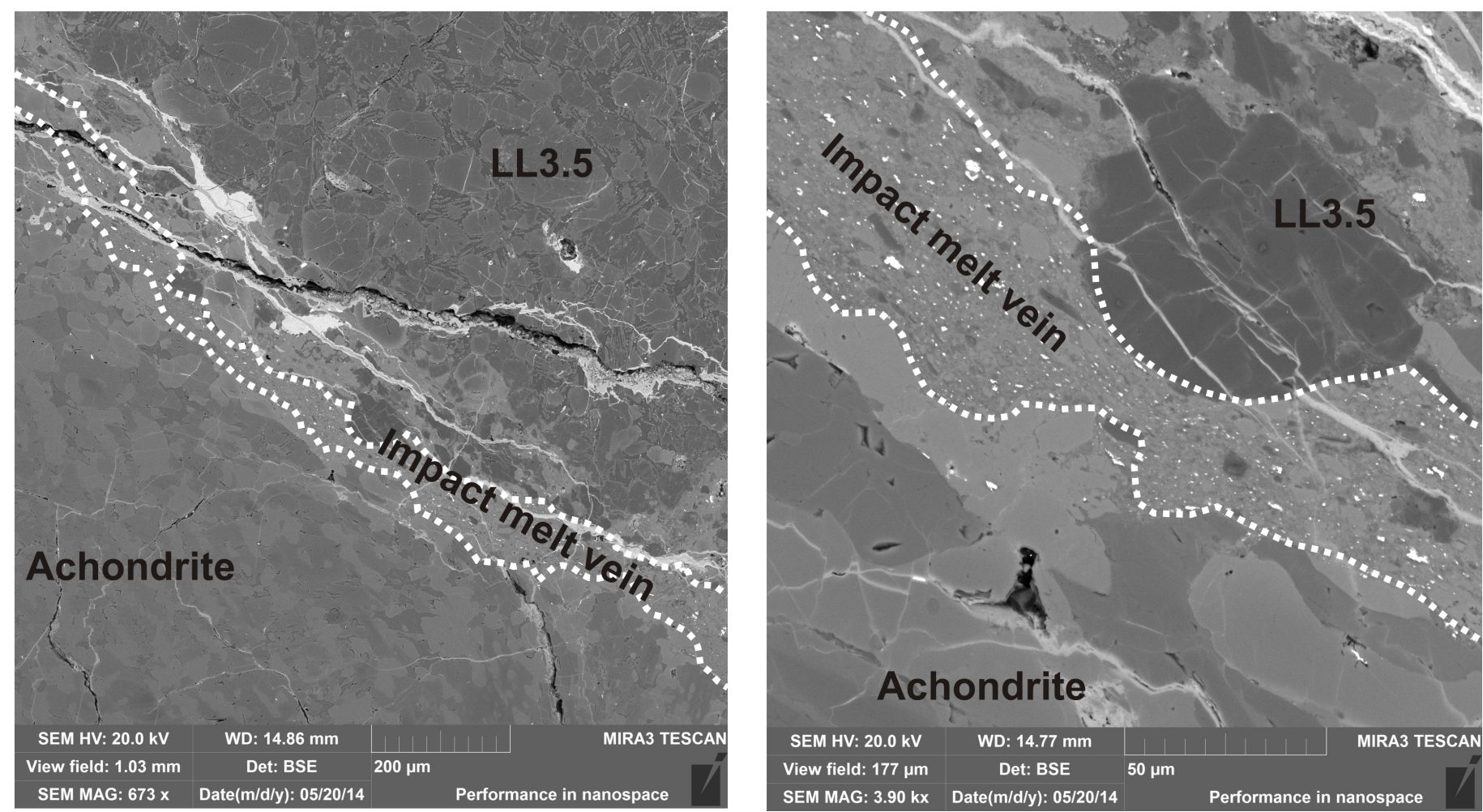

Fig. 13. Contact between LL3.5 lithology and achondritic clast of meteorite M2 - Benešov (a). The achondritic clast is cemented to LL3.5 lithology by an irregular vein of impact melt.


Fig. 14. Backscattered electron images documenting the texture of H5 lithology of meteorite M1 - designated as Benešov (b). All Fe-Ni phases and troilite are strongly oxidized from weathering processes, and weathering products also fill visible microfractures.

Otherwise the assignment of meteorites to bolides can always be doubtful, and we have to rely on more or less conclusive indirect evidence. This is also the case of the Benešov bolide and meteorite fall. Below we discuss some important evidence why the meteorites we recovered in the predicted area belong to the Benešov bolide.

For most meteorites that are designated as the falls, the temporal or spatial proximity is the crucial condition. The poorer 
the location of the bolide, the closer the temporal proximity (i.e., the recovery of the meteorite within weeks after the bolide appearance) that is needed. Benešov is the opposite extreme. The bolide was located very precisely $(\sim 12 \mathrm{~m})$ and the darkflight was computed rigorously, so that the location of meteorites was predicted with a precision of about $100 \mathrm{~m}$ or even better. Under these circumstances the temporal proximity is not crucial, since it is very unlikely that other meteorites would fall in the same location within a few decades. We tried to estimate the probability of such hypothetical coincidental falls. To estimate this, we have to know the number $N$ of meteorite falls in any area per year in a mass range corresponding to the Benešov meteorites (about $10 \mathrm{~g}$ ). Halliday et al. (1989) used data from 56 observed falls from the Meteorite Observation and Recovery Project (MORP) with a computed terminal mass of the largest fragment of at least $50 \mathrm{~g}$ (individual errors might be in error by factors of 3 or 4 , but a systematic error larger than a factor of 2 is unlikely). The determined flux in an area of $10^{6} \mathrm{~km}^{2}$ provides nine falls per year (already corrected to the whole year) with a total mass of meteorites higher than $1 \mathrm{~kg}$, or 58 falls per year with a total mass of meteorites higher than $100 \mathrm{~g}$. Halliday et al. (1989) also discussed an evident deficiency of small meteorites (smaller than about $1 \mathrm{~kg}$ ). The mass range of $10 \mathrm{~g}$ meteorites is included in MORP data because of the uncertainty of the computed terminal mass of the largest fragment, and thus there is no need to extrapolate the number of meteorite falls to smaller masses. In the case of Benešov meteorites, the impact area in which the meteorites were recovered is smaller than $250 \times 70 \mathrm{~m}$, which is $1.75 \times 10^{-2} \mathrm{~km}^{2}$. One meteorite fall can therefore be expected to occur in this area in about $10^{6}$ years. If we assume that one fall (Benešov bolide) has already occured and we need to know a probability that there was or will be another fall (unknown to us) in the same area within one decade (to provide a comparable degree of weathering of the meteorites), the result is the probability of one particular fall corrected by the time between the falls, which is on the order of ten years. The resulting probability is only $10^{-5}$. If we considered that some meteorite falls can form larger strewn fields, the probability might increase to $10^{-4}$. However, such events would certainly belong to the superbolide category, and as mentioned in the introduction, these events are very rare even in general (Brown et al. 2002, 2013). Moreover, it is highly improbable that an event like that would not be registered somehow. The reason is that the Benešov impact area is located close to the Ondřejov observatory and is situated approximately in the center of the Czech part of the European Fireball Network (EN). This area has been systematically monitored for bolides in all clear nights since 1951 photographically, and since 1999 in all nights including bad-weather periods also photoelectrically (Ceplecha 1952, 1977; Spurný et al. 2006). We thus know that except for the described case, no other meteoritedropping fireball was recorded by the EN above the Benešov area. Moreover, this field of science has a long tradition and publicity in the Czech Republic, which started long before our systematic observations. This means that we regularly receive reports of visual observations about any brighter fireball, including daytime events (there were also a few large daytime fireballs above the Czech Republic in the past few decades, but none above the Benešov impact area). Furthermore, the probability that we would miss one meteorite fall in this particular area is thus even much lower than the estimated value of $10^{-5}$. It is theoretically possible that some not-so-bright meteorite-dropping fireball that occurred during daytime or poor weather was still missed. However, such a hypothetical event would drop only a few small meteorites. Assuming them to land on the same field as Benešov in combination with the rigorously determined very low probability is beyond any reasonable expectations.

Other indirect evidence can be obtained from meteorite analyses. The meteorites are, unfortunately, quite small and degraded by weathering. It is important to note that the character of the weathering (especially the degree of oxidation of sulphides and Fe-Ni phases) of all fragments is very similar. Stony meteorites can weather quickly in Central-European climate because of the frequent rainfall and high temperature changes between summer and winter, and in this particular case also because of very intensive agricultural activity. Any difference in the weathering grade between fragments of two hypothetically different falls within a range of a decade in this area would be easily recognizable. The similar degree of weathering of the two Benešov lithologies supports our opinion that the meteorite fragments represent a single fall.

Isotopic analysis, which could restrict their terrestrial residence time in a rigorous way, is not possible because of the long time after the fall and the high degree of weathering. The high degree of weathering is also problematic for measuring the cosmic-ray exposure (CRE) ages for both lithologies, to support the idea that samples are coming from the same fall. However, the CRE ages of polymict meteoritic breccias could be more complex since their particular components could have undergone multistage exposures before they were buried in parent bodies or in meteoroids (see Eugster et al. 2006). The CRE ages would therefore not bring unambiguous evidence that the meteorites did or did not come from the same object.

The fact that the meteorites are of different types would have produced significant controversy several years ago. Nevertheless, the large heterogeneity of the Almahata Sitta meteorite fall (Bischoff et al. 2010) and the surface heterogeneity of asteroid (21) Lutetia (Barucci et al. 2012) demonstrated that mixing of the material in the asteroid belt is possible. The relation of different lithologies in meteorites, which are believed to come from the Almahata Sitta meteorite fall, was described on the basis of a comparison of CRE ages (analyzed were only samples of ureilitic lithologies, Welten et al. 2010) and an analysis of short-lived cosmogenic nuclides (together with ureilitic lithologies, two chondritic lithologies were also analyzed, Bischoff et al. 2010). Unfortunately, because of the long time after the fall and the strong weathering we cannot use the same approach for the Benešov meteorites and analyze the short-lived cosmogenic nuclides. However, the fact that the meteorites are of different types therefore does not represent a reason to dispute that they came from a single fall.

The last supporting argument for the connection of the Benešov bolide with the recovered meteorites is the analysis of spectral records. This is the first time that very detailed spectral records exist for a bolide that terminated in a meteorite fall. The Benešov spectrum was inspected by Borovička \& Spurný (1996). In their Table VI, relative abundances in the radiating gas of several elements ( $\mathrm{Na}, \mathrm{Mg}, \mathrm{Ca}, \mathrm{Ti}, \mathrm{Cr}, \mathrm{Mn}$, and $\mathrm{Ni}$ ) to $\mathrm{Fe}$ were presented for several altitudes. However, because of the calibration and measurement problems and the simplifications used (thermal equilibrium), the abundances were uncertain by a factor of three. The authors concluded that the Benešov body was chondritic, which agrees with both types of the recovered meteorites, but until the analytical methods are improved significantly, the spectra are not sufficient to reveal whether one type was prevailing.

From these aspects we can conclude that all recovered meteorites were dropped by the Benešov bolide in 1991. The main reasons can be summarized as follows: they were found exactly 
where predicted, their mass is in the predicted range, their weathering stage is very similar and consistent with lying in the wet ground for the expected period, their composition is consistent with the bolide spectrum, and the probability of two recent coincident falls in the given area is extremely low.

\section{Conclusions}

This result is in many aspects pioneering. We proved that in some special cases it is still possible to predict and find meteorites a long time after the bolide observation. In this particular case the time span between the bolide and meteorite find was exactly 20 years. This happened never before. As we showed, this important result is a product of applying improved methods and the rich experience achieved by analyzing of several instrumentally observed meteorite falls since the beginning of this century (Morávka, Neuschwanstein, Villalbeto de la Peña, Bunburra Rockhole, Jesenice, Košice, and Mason Gully). We showed that this result was achieved in a strictly rigorous way. We first explained unsuccessful attempts connected with searches of meteorites in the weeks and years after the fall. Then we introduced our new atmospheric trajectory solution, and suggested a new scenario for the whole event. In the last step we predicted a new impact area where meteorites could be found, and validated this new scenario by finding meteorites exactly according to this prediction.

One very important result arising from this new analysis of the Benešov event is the fact that most of the mass that survived the atmospheric flight was not in the form of larger pieces $(>100 \mathrm{~g})$, as has long been thought, but in the form of a huge number of small gram-sized pieces. We estimate that for the Benešov case the total mass of all pieces larger than $100 \mathrm{~g}$ could reach $10 \mathrm{~kg}$ at most but the total mass of the gram-sized meteorites was very probably on the order of hundred kilograms, that is certainly more than ten times larger. From the recent analyses of some other large events of the superbolide category, such as Almahata Sitta (Jenniskens et al. 2009), Košice (Borovička et al. 2013a), or even Chelyabinsk (Borovička et al. 2013b), it seems that this is a quite common behavior especially for bodies that exhibit large flares in the last third of their atmospheric flights. This aspect should be taken into account to choose the most appropriate search strategy for any future large meteorite fall.

The second, probably still more important result is connected with the analysis of the meteorites themselves. Although we found only four small highly weathered meteorites with a total mass of about $12 \mathrm{~g}$, it was enough not only to classify them, but surprisingly also to discover their differences. This case clearly shows that larger meteoroids can be compositionally very complex bodies. We discovered that the Benešov meteoroid consisted of at least three different types of material because we distinguished three different lithologies (LL3.5 and H5 ordinary chondrite and primitive achondrite) in the recovered samples. Evidently, the parent meteoroid originated from an asteroid that was significantly reprocessed by collisions with other asteroids in the main belt. This finding nicely corresponds with the atmospheric behavior of the meteoroid, as discussed by Borovička et al. (1998b). The high deceleration of the bolide led to the conclusion that the meteoroid disrupted into smaller $(\sim 100 \mathrm{~kg})$ fragments at the beginning of the atmospheric entry. The meteoroid was therefore an aggregate of loosely bound pieces. A similar meteorite heterogeneity was also observed for the Almahata Sitta meteorite, as described in Bischoff et al. (2010). This case also implies that it is very useful to study as many fragments as possible from one fall because there can be significant differences among them.

As a result of the small but in some aspects considerable change of the atmospheric trajectory data, we also recomputed the heliocentric orbit of the Benešov meteoroid and reported new revised orbital elements and radiant position.

In summary, we conclude that although it seemed to be a hopeless case, 20 years after the event we were finally able to find a way and method to recover remnants of the original Benešov meteoroid. Thanks to our rigorous procedure and scenario in combination with favorable circumstances, we revealed the probably most interesting and important Benešov mystery the heterogeneity of the Benešov parent body.

Acknowledgements. This work was supported by the project RVO:67985815, by the Praemium Academiae of the AS CR, by the GA grants GA CR 205/08/0411 and P209/11/1382 and the EU grant MRTN-CT-2006-035519. We are very much indebted to L. Trubač for the search permit in the impact area, M. Mlejnský and his searching group Archeo LP 2010 for important help in searching and also for valuable advice connected with the use of metal detectors, M. Janáč for documenting all our effort in the field and laboratory and all those who helped us with searching, namely (in alphabetical order) H. Ceplechová, D. Čapek, K. Hornoch, J. Keclíková, P. Koten, P. Kušnirák, J. Shrbený, P. Scheirich, L. Smolíková, A. Spurná, R. Štork, V. Vojáček, and H. Zichová. Our special thanks go to D. Čapek, who in addition to searching also made the primary selection, cleaning, and cataloging of most of the collected samples. We also gratefully acknowledge valuable suggestions and helpful comments by the referee M. D. Campbell-Brown.

\section{References}

Barucci, M. A., Belskaya, I. N., \& Fornasier, S. 2012. Planet. Space Sci., 66, 23 Berezhnoy, A. A., \& Borovička J. 2014, Chemistry of the Benešov meteoroid. Proc. of the Meteoroids 2013 Conf., in press

Bischoff, A., Horstmann, M., Pack, A., et al. 2010, Meteor. Planet. Sci., 45, 1638 Bland, P. A., Spurný, P., Towner, M., et al. 2009, Science, 325, 1525

Borovička, J., \& Spurný, P. 1996, Icarus, 121, 484

Borovička, J., Spurný, P., \& Keclíková, J. 1995, A\&A, 112, 173

Borovička, J., Popova, O. P., Nemtchinov, I. V., et al. 1998a, A\&A, 334, 713

Borovička, J., Popova, O. P., Golub, A. P., et al. 1998b, A\&A, 337, 591

Borovička, J., Spurný, P., Kalenda, P., et al. 2003, Meteor. Planet. Sci., 38, 975

Borovička, J., Tóth, J., Igaz, A., et al. 2013a, Meteor. Planet. Sci., 48, 1757

Borovička, J., Spurný, P., Brown, P., et al. 2013b, Nature, 503, 235

Brown, P., Spalding, R. E., ReVelle, D., et al. 2002, Nature, 420, 314

Brown, P. G., Assink, J. D., Astiz, L., et al. 2013, Nature, 503, 238

Ceplecha, Z. 1952. Bull. Astron. Inst. Czechosl., 3, 53

Ceplecha, Z. 1961, Bull. Astron. Inst. Czechosl., 12, 21

Ceplecha, Z. 1977, Bull. Astron. Inst. Czechosl., 28, 328

Ceplecha, Z. 1987, Bull. Astron. Inst. Czechosl., 38, 220

Ceplecha, Z., \& ReVelle, D. O. 2005, Meteor. Planet. Sci., 40, 35

Ceplecha, Z., Spurný, P., Borovička, J., \& Keclíková, J. 1993, A\&A, 279, 615

Eugster, O., Herzog, G. F., Marti, K., \& Caffee, M. W. 2006, Meteorites and the Early Solar System II, eds. D. S. Lauretta, \& H. Y. McSween Jr. (Tucson: University of Arizona Press), 829

Halliday, I., Blackwell, A., \& Griffin, A. 1978, J. Royal Astron. Soc. Canada, 72, 15

Halliday, I., Blackwell, A., \& Griffin, A. 1989, Meteor. Planet. Sci., 24, 173 Jenniskens, P., Shaddad, M. H., Numan, D., et al. 2009, Nature, 458, 485

McCrosky, R., Posen, A., Schwartz, G., et al. 1971, J. Geophys. Res., 76, 4090 Spurný, P. 1994. Planet. Space Sci., 42, 157

Spurný, P. 1997, Planet. Space Sci., 45, 541

Spurný, P., Borovička, J., \& Ceplecha, Z. 1991, WGN, 19, 99

Spurný, P., Oberst, J., \& Heinlein, D. 2003, Nature, 423, 151

Spurný, P., Borovička, J., \& Shrbený, L. 2006, Automation of the Czech Part of the European Fireball Network: Equipment, methods and first results, Proc. IAU Symp., 236, 121

Spurný, P., Borovička, J., Kac, J., et al. 2010, Meteor. Planet. Sci., 45, 1392

Spurný, P., Bland, P. A., Shrbený, L., et al. 2011, 74th Meeting of the Meteoritical Society, 5101 (abstract)

Spurný, P., Bland, P. A., Shrbený, L., et al. 2012, Meteor. Planet. Sci., 47, 163 Stöeffler, D., Keil, K., \& Scott, E. R. D. 1991, Geoch. Cosmoch. Acta, 31, 747

Trigo-Rodríguez, J. M., Borovička, J., Spurný, P., et al. 2006, Meteor. Planet. Sci., 41, 505

Welten, K. C., Meier, M. M. M., Caffee, M. W., et al. 2010, Meteor. Planet. Sci., 45,1728

Wlotzka, F. 1993, Meteoritics, 28, 460 (abstract) 